\title{
El guión de cómic
}

\author{
Gerardo Vilches
}

Diminuta Editorial, 2016

$\mathrm{D}$ ICE Neil Gaiman que un guión de cómic es una carta al artista. Escritura y dibujo se relacionan, en el cómic, de una manera específica que no encuentra parangón - pero sí ciertos paralelismos- en el guión para el cine y la televisión (es decir, para la imagen en movimiento). Cuestiones como esta, y otras que detallaremos a continuación, son las que aborda Gerardo Vilches (Madrid, 1980) en El guión de cómic, una obra en parte conversacional que se centra en las letras y en algo más que la "palabra gráfica». Es decir, en todo lo que rodea a la gestación de una historia, antes de su materialización ilustrada: idea, argumento y personajes, sinopsis, estructura, escaleta, escenas, realización de diálogos. Lo de conversacional tiene que ver con el plan-

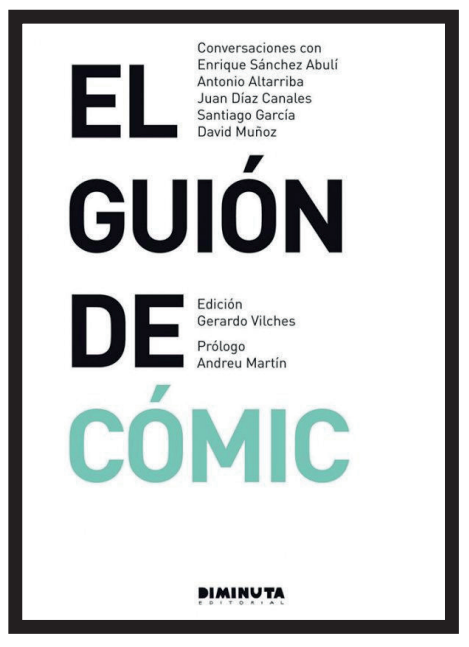
teamiento del libro, para el cual Vilches se ha entrevistado con cinco guionistas de cómic de diferentes generaciones, escuelas, intereses personales, estilos y trayectorias. Enrique Sánchez Abulí (Palau-del-Vidre, 1945), Antonio Altarriba (Zaragoza, 1952), Juan Díaz Canales (Madrid, 1972), Santiago García (Madrid, 1968) y David Muñoz (Madrid, 1968) van contestando a las preguntas de un entrevistador comprometido con la pedagogía en relación con una labor necesitada de divulgación porque... ¿qué es lo que hace un, o una, guionista de cómic? ¿Cómo se trabaja con quienes dibujan? ¿Ha estado siempre reconocida esta actividad? ¿Cuál ha sido la evolución de la escritura, en el engranaje del cómic tradicional? El guión de cómic no solamente responde estas preguntas, sino que también ejemplifica, de alguna forma, cinco formas de abordar una disciplina artística de colaboración; haciendo asimismo historia, como puede comprobarse en las dos primeras conversaciones mantenidas con Sánchez Abulí y Altarriba, los más veteranos de la clase.

Antes, sin embargo, Vilches elabora una historia exprés que en una treintena de páginas nos coloca en situación, partiendo de las formas satíricas del siglo XIX y de un hito relevante en la evolución de las tiras de prensa: el paso de la historieta autoconclusiva a la continuidad de las historias y la aparición de ghost writers, escritores a la sombra del dibujo. Señala, igualmente, cómo la estandarización del guión aparece con el comic book — cuadernillo «emancipado» de otros medios-, sometido a un proceso fabril exigente con unos deadlines de vértigo. La autoría, como señala Armonía Rodríguez (una de las pocas guionistas que 
aparecen a lo largo de la obra) queda sepultada bajo seudónimo, si bien esto cambiará a mediados del siglo Xx, cuando los superhéroes se ven superados por contenidos diversos, entre el $s c i-f$, el género policíaco y el terror. Vilches señala la relevancia de artistas como Harvey Kurtzman, que amplió las tareas del guión, atribuyendo a la persona responsable cuestiones como la distribución de las viñetas o la postura de un personaje en un plano concreto determinado. Los modos de trabajo en Europa, con guionistas de prestigio - René Goscinny y Jean-Michel Charlier como punta de lanza en la bande dessinée-, y la irrupción de la metodología Marvel, con Stan Lee como antítesis de Kurtzman con respecto a la idea de lo que tenía que ser un escritor de cómics, son explicados por Vilches con testimonios en primera persona de los propios artistas, añadiendo además ejemplos de tebeos y voces teóricas de prestigio.

Las diferentes concepciones de lo que debe ser el guión en un medio eminentemente visual se ven reflejadas en declaraciones de guionistas como Chris Claremont, que hablaba en los años ochenta de contar «estados mentales» y «actitudes», es decir, aquello que en puridad sería in-ilustrable. Es en esta década cuando surge, por un lado, una autoría completa con Frank Miller como autor-paradigma que revoluciona la narración y la secuenciación de las historietas, mientras que, por otro, se produce la llamada «invasión británica», con escritores como Alan Moore que llevan la disciplina artística a una densidad narrativa sin precedentes. Llegados a este punto, y antes de alcanzar en esta introducción histórica a la novela gráfica como formato, a priori, tendente a esa autoría total (Jaime y Beto Hernandez, Alison Bechdel, etcétera), es necesario referirse al gran tema que recorre, con sus acuerdos y desacuerdos, encuentros y desencuentros, amores y odios, la propuesta de Vilches: la relación entre guionistas y dibujantes. A este matrimonio de conveniencia temporal se refieren los entrevistados inevitablemente, claro está.

La experiencia resulta, no obstante, tan individual como lo es cada una de las firmas que aquí aparecen; abunda, además, la idea de la necesidad de trabajar con dibujantes a quienes se conoce personalmente, dado que eso se reflejará en el resultado final de la historia (si ha habido química dialogada entre unos y otros). Cocinar un guión requiere un trabajo previo importante (toma de notas, documentación), un andamiaje en el que cada pieza ha de estar en su sitio, tanto para ir narrando la historia como para no caer al vacío en mitad del relato. $\mathrm{El}$ reto parte de lo literario y deviene en producto artístico visual, y las conversaciones de Vilches con estos profesionales así lo atestiguan; de ahí que sea en los ejemplos gráficos, con páginas de guión contrapuestas a la página final, donde mejor puede apreciarse el éxito de esta sinergia.

Hay preguntas que se repiten, puesto que son claves en la labor de la escritura (por ejemplo, la referida al margen que deja el escritor al dibujante, en especial cuando se habla de guiones sumamente detallados), pero cada entrevista se reviste del yo y las circunstancias del autor. Pioneros como Abulí, creador de Torpedo, hablan de cuestiones tan pertinentes, a las luces de este siglo, como la de la «impublicabilidad» de un cómic que ahora mismo sería tildado de incorrecto, políticamente; o del peso del estereotipo en la creación de determinados personajes en la España franquista de finales de los sesenta. 
Altarriba — que comparte con Santiago García su faceta teórica, en el caso del zaragozano como académico en la Universidad del País Vasco-, habla del guión como «estrategia de secuencialización y distribución en viñetas», descubriéndonos soluciones técnicas como parte de la narrativa en las que la escritura y el dibujo confluyen (aunque el plano sea mudo), y reivindicando el cómic experimental como gran inspirador, amén del «patrimonio gráfico» que crece progresivamente. Las notas a pie de página son lo suficientemente abundantes como para no dar por sentado nada: ningún conocimiento relacionado con artistas, editoriales, géneros o cualquier otro dato que el editor considere destacable. Queda clara la visión ilustrada, en el sentido dieciochesco de la palabra, de un título necesario e interesante para quienes se interesen en el guión de manera transversal, incluso.

Transversal puesto que las diferencias entre el guión en el audiovisual y el cómic aparecen en las charlas con Díaz Canales y David Muñoz, ambos profesionales de la escritura para cine, animación y televisión. El primero, que desde 2015 se ocupa del primer álbum de Corto Maltés tras la muerte de Hugo Pratt, concibe el guión como un trabajo abierto, de equipo: una interacción entre ideas conceptuales y visuales en la que ha de primar el consenso. La construcción biográfica, física y psicológica de los personajes, amén de la deuda con la autobiografía por parte del autor, son otras de las cuestiones que se tocan. Muñoz (que ha trabajado en guiones de películas como El espinazo del diablo, de Guillermo del Toro) señala la complicación que entraña la labor creativa sobre un espacio impreso en el que el guionista acumula funciones, a diferencia que en el audiovisual, donde hay un perfil para cada cosa (dirección, dirección de arte, montaje). «El texto existe en el espacio, y eso lo cambia todo", dice este autor, que incide bastante en la planificación de la historia para que a la hora de trasladarla al papel se ajuste completamente (en los formatos cerrados como el álbum europeo más todavía).

Santiago García, por su parte, recurre a la cartografía como metáfora. Así, el guión sería un mapa de trabajo que para el madrileño arranca en forma de pensamiento obsesivo que a posteriori empieza a armarse en la fase documental. El cruce de caminos entre texto y argumento, lo gráfico y lo visual, dentro de un proceso autoral que es conjunto, es un tema que ocupa gran parte del texto de la entrevista a este guionista, que afirma, taxativo, y en respuesta a la pregunta de Vilches en torno a la valoración por parte del público: «solo me preocupa lo que piensen del resultado final». Suponemos que la finalidad de El guión de cómic era arrojar luz sobre esa «zona oscura del cómic» que, en palabras de Altarriba, sigue siendo el territorio del guión. Vaya si lo ha conseguido. Entretenidamente y con creces.

Isabel Guerrero

Isabel Guerrero (Málaga, 1975). Licenciada en Periodismo y máster en Desarrollos Sociales de la Cultura Artística por la Universidad de Málaga (A Different Kind Of Tension. Discursos artísticos, marginales y musicales en las escenas del punk, fue su trabajo fin de máster). Su proyecto fin de carrera se tituló Los fanzines musicales en España en los años 90. Análisis de un proyecto de comunicación alternativa. Periodista y crítica cultural transversal, copywriter, escritora de articulos, relatos, poemas, canciones. Batería y cantante de Esplendor, con quienes ha 
publicado un EP, Tara (Clifford Records, 2015). Ha escrito y colaborado en medios de comunicación de diferentes ámbitos (M80 Radio, El Correo de Málaga, Metrópoli, Radio 3, Canal Sur, Diario SUR). Ha trabajado para empresas de comunicación, productoras, agencias de publicidad, organizaciones sin ánimo de lucro, profesionales y artistas. En la actualidad es colaboradora del periódico Málaga Hoy (tiene sección de arte en Cultura, La Última Mona) y en Rockdelux (Cómics y Libros Pop). 